\title{
A Big Data Analytics Approach for Dynamic Feedback Warning for Complex Systems
}

\author{
Wenrui Li, ${ }^{1,2}$ Menggang Li $\mathbb{C}^{2,3,4}$ Yiduo Mei, ${ }^{5}$ Ting Li $\mathbb{C}^{1},{ }^{1}$ and Fang Wang $\mathbb{C}^{1,2}$ \\ ${ }^{1}$ School of Economics and Management, Beijing Jiaotong University, Beijing 100044, China \\ ${ }^{2}$ Beijing Laboratory of National Economic Security Early-Warning Engineering, Beijing Jiaotong University, \\ Beijing 100044, China \\ ${ }^{3}$ National Academy of Economic Security, Beijing Jiaotong University, Beijing 100044, China \\ ${ }^{4}$ Beijing Center for Industrial Security and Development Research, Beijing Jiaotong University, Beijing 100044, China \\ ${ }^{5}$ Postdoctoral Programme of China Centre for Industrial Security Research, Beijing Jiaotong University, Beijing 100044, China
}

Correspondence should be addressed to Menggang Li; mgli1@bjtu.edu.cn and Ting Li; 15113169@bjtu.edu.cn

Received 23 June 2020; Revised 14 September 2020; Accepted 21 September 2020; Published 6 October 2020

Academic Editor: Abd E. I.-Baset Hassanien

Copyright (c) 2020 Wenrui Li et al. This is an open access article distributed under the Creative Commons Attribution License, which permits unrestricted use, distribution, and reproduction in any medium, provided the original work is properly cited.

With the development of science and technology, the application of big data is becoming more and more widespread, and it has gradually expanded to various fields such as economy and commerce. Since the 2008 international financial crisis, the mainstream economics has shown deficiencies to a certain extent. On the one hand, the expressions pursued by mainstream economic theories are too strict, restricting its processing capabilities. On the other hand, the linearization method ignores the diversity, complexity, and variability of changes in the economic system, which may ignore the emergence of some serious crises. Due to the increasing distance between theoretical models and practice, theoretical models cannot guide the practice and sometimes even mislead the latter. In this paper, we propose a method of dynamic feedback early warning based on big data, which uses the LPPL model to fit parameters. Finally, we used this method to analyze the case of the A-share disaster. The research results show that the method makes the early warning coefficients of dynamic and complex systems more scientific and accurate.

\section{Introduction}

A complex system is an organic entity that interacts with various parts, not a simple addition and mechanical combination of parts [1]. Therefore, people's understanding of locality cannot be pieced together to understand the overall laws of complex systems.

In the face of complex systems, another method commonly used by humans is to decompose complex problems layer by layer, cut them into tiny fragments, analyze the fragments in depth, and infer the overall situation. However, the close connection and interaction between the various parts of the system were also destroyed during the cutting process.

Human society is a typical complex system. The study of this system, especially the economic aspects, is more a partial analysis and decomposition study. Various traditional economic theories are mostly concentrated in a certain field, such as demand, supply, and currency. In addition, due to the complexity of economic systems, many analyses cannot be simply proved by data nor can they be summarized by simple causality because in complex systems, many factors are both causes and results. In this way, the interpretation of economic phenomena by various economic theories is not convincing. For example, it has been more than 80 years since the Great Depression of 1929, and economists still do not have a satisfactory explanation of the root cause of the Great Depression and are still arguing. The financial crisis of 2008 allowed this debate to continue to heat up, with each side holding its own word and giving up, and this debate will continue in the future $[2,3]$.

Economists are immersed in economic phenomena, data, models, and theories. They seem to be the most authoritative people who study and solve economic problems. 
But what would happen if we looked at economic issues from a completely unrelated perspective? What would come to a conclusion if someone who was familiar with cybernetics but not familiar with economics observed the economic crisis? First of all, the noneconomic professional may not only study a certain part nor study the system decomposition. First, he considers the system as a "black box" and observes the entire system by observing input and output features. Second, he may study the internal structure and connections of the system.

From the perspective of system control, a periodic economic crisis is a periodic shock. If a system enters a periodic oscillation without external input disturbance, this system is likely to have positive feedback [4]. The shock comes from the internal structure of the system, not the changes in input and output. It is wrong to emphasize that changes in certain parameters of the system cause the entire system to oscillate, such as insufficient demand, excessive supply, insufficient investment, credit expansion, credit contraction, and so on. In order to study the periodic oscillation of the system, the structure of the system must be studied to find the positive feedback mechanism inside the system.

\section{Related Work}

Risks arise from imbalances in supply and demand, both purely quantitative and quality-effective. The traditional risk determination model $[5,6]$ is based on the assumptions of rational expectations, price equilibrium, and market competition, but these factors cause the theory to be inconsistent with the real economy. The economic system is a complex adaptive system; for example, in Keynes's demand theory, residents must have complex self-adaptation in order to adjust their decisions, including demand and investment, according to the changing environment. Similarly, in Schumpeter's innovation theory, only if a company has complex self-adaptability can it discover and create nonequilibrium and continuously pursue technological innovation and capital accumulation in pursuit of high profits.

An important method for studying complex adaptive systems in cybernetics is to use a two-way feedback mechanism. Therefore, we propose to use a two-way feedback mechanism in cybernetics to warn of risks in economic systems. We propose that the risk originates from the migration of the internal mechanism of the system (from negative feedback to positive feedback). The construction of dynamic feedback models and early risk warning simulation based on big data platforms is the focus of this study. As shown in Figure 1, we divide the system operation cycle into nonrisk cycle and risk cycle according to the dynamic feedback mechanism $[7,8]$. We take a semaphore-based dynamic feedback model as an example; when the model is negative feedback, the dynamic feedback model we propose is the traditional equilibrium model. At this time, the system is in a nonrisk cycle. When the model is positive feedback, it is a selforganizing collaborative model that shows strong reflexive characteristics, at which time the system is in a risk cycle.
Our research shows that the negative feedback system conforms to the traditional model of supply and demand and the positive feedback system conforms to the reflexivity theory proposed by Soros $[9,10]$.

In addition, the financial bubble $[11,12]$ refers to an economic phenomenon in which the price of a financial asset (or a series of financial assets) undergoes a wave of rise and the market price reflects greater than the upward movement of its actual value. The phenomenon that prices follow a power law and grow faster than exponential growth is called a bubble. Bubble price momentum has gradually increased over time. According to the direction and intensity of price momentum, we divide bubbles into four categories:

Bubble: the price trend rises, and the price momentum gradually increases, as shown in Figure 2

Negative bubble: the price trend declines, and the price momentum gradually weakens, as shown in Figure 3

Reversing bubble: the price trend drops, and the price momentum gradually increases, as shown in Figure 4

Reverse negative bubble: the price trend rises, and the price momentum gradually weakens, as shown in Figure 5

After the bubble, the self-organization of participants in the market through the consensus of the market will form a positive feedback effect and enter the bubble mode. The bubble is not only self-sufficient but also continuously enlarged (the negative bubble is continuously shrinking, that is, the process of debubbling). When the financial bubble trend reached a critical level, although the main participants agreed, the market could no longer withstand the perturbation of a small number of participants, leading to a collapse. In fact, participating in a bubble and trading in a trend is a rational behavior because the risk of a crash will be compensated by the positive returns brought by the financial bubble. At the same time, once a bubble is formed, it will last for a long time, and the burst of the bubble is just a point at the end of this cycle.

In summary, in recent years, with the emergence of complex systems science, the impact of risk interaction behavior has been gradually discovered. However, the main reason for the difficulty of accurate prediction and early warning of economic risks is that traditional risk prediction relies mainly on traditional mathematical modeling tools and lacks the support of effective theoretical models and data algorithms for the interaction and evolution of complex risks. The development and widespread application of big data technology has made various economic systems accumulate huge amounts of data resources. It also makes multidomain and cross-modal data collection and fusion analysis possible [13]. This provides valuable data resources and technical support for comprehensive perception of complex systems, fusion analysis of risk elements, accurate prediction of risk evolution, and timely warning of risks [14]. At the same time, how to effectively extract the characteristics of risk emergence, mutation, evolution, and outbreak from these economic big data so as to realize the intelligent 


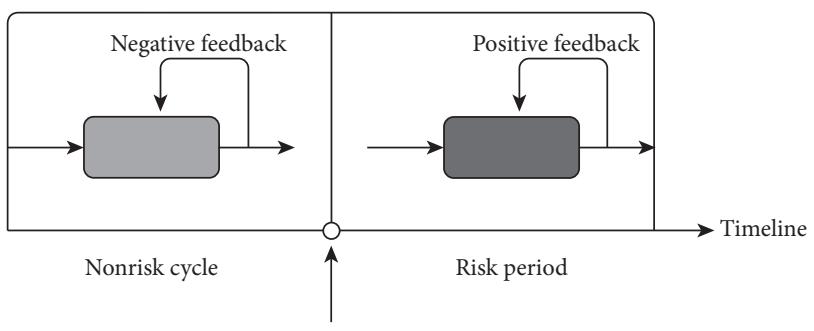

Figure 1: The full risk cycle formed by the feedback mechanism.
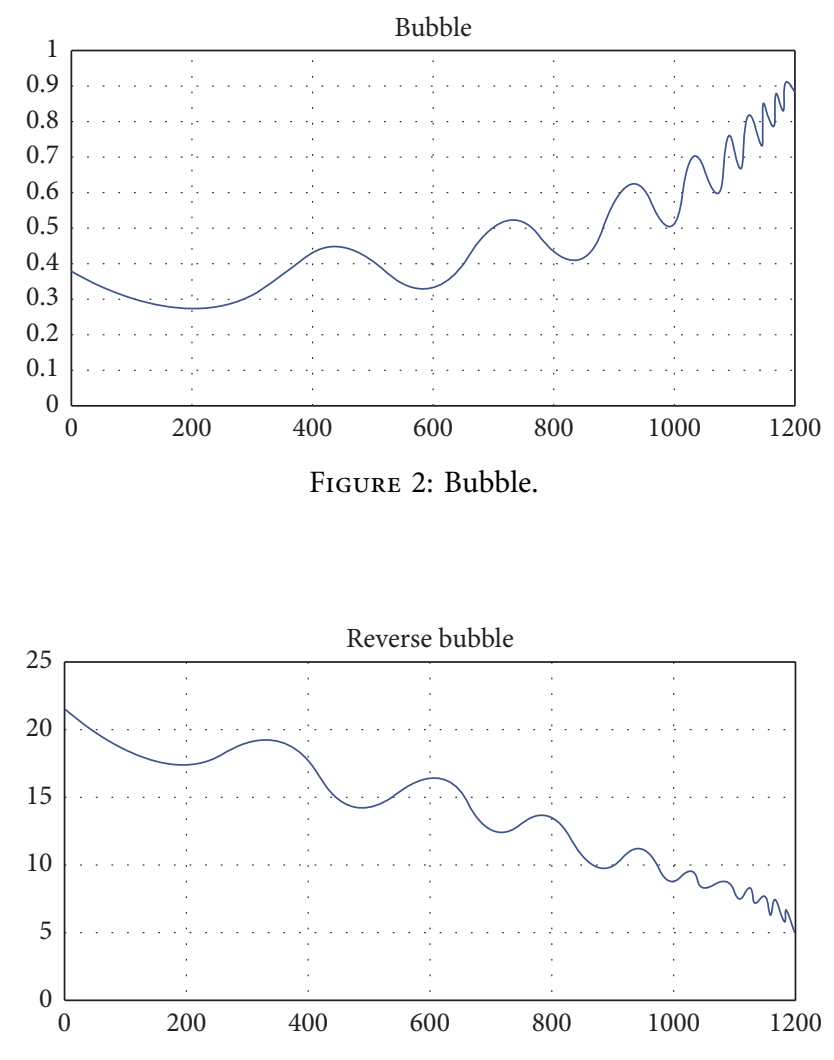

Figure 3: Reverse bubble.

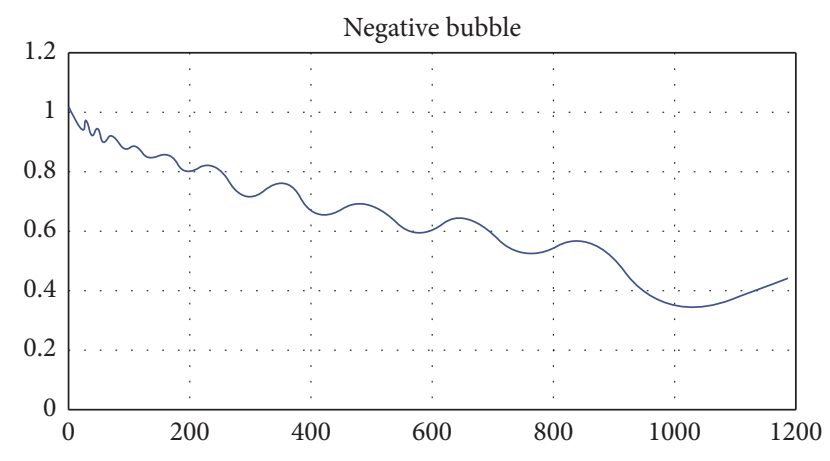

Figure 4: Negative bubble.

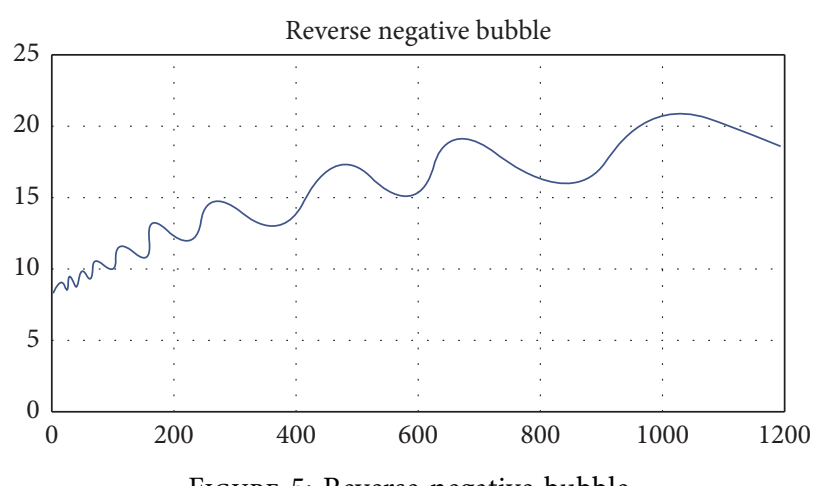

FIGURE 5: Reverse negative bubble.

prediction and early warning of complex economic risks has increasingly become a new technical challenge.

\section{Logarithmic Periodic Power Law Model}

Didier Sornette is engaged in the research of geophysics [15]. However, he found that the formation and bursting of financial market bubbles have many similarities with earthquakes and are self-organizing behaviors of complex systems. Professor Sornette then proposed to use the LPPL (log-periodic power law) model (logarithmic periodic power law model) commonly used in the study of geophysics and critical phenomena to study the bubbles in the financial field.

3.1. Related Research. In 1996, Sornette proved through empirical studies that the bubble showed a log-periodic oscillation during the trend towards collapse. In 2001, he further proposed that the stock market bubble can be found in the logarithmic periodic power law model and confirmed this conclusion through empirical research on emerging stock market bubbles. The concept of antibubbles was first proposed by a paper published by Johansen and Sornette in 1999. In this paper, they used a third-order Landau model to predict the trend of the Nikkei [16] in 1999 and successfully predicted it. This reflects the rebound of the Nikkei and its decline again in early 2000, and their predicted rebound is in line with the actual range. Later, Wei-Xing Zhou and Didier Sornette studied the trend of the $S$ \& $P$ index after the burst of the new economic bubble at the end of 2002 and found that the U.S. stock market has entered an antibubble stage and further found that there is a global antibubble mechanism in developed western countries. Domestically, Zhang Wei and Huang Xing conducted an empirical analysis of the Shanghai and Shenzhen stock markets through R/S [17], revealing the nonlinear characteristics of China's stock market volatility. Zhou and Professor Sornette observed the "super index" family bubble characteristic of Chinese housing prices [2]. At that time, they predicted based on data up to 20 years, China house prices will rise until 2008, after which the bubble burst. The log-periodic power law model has two common features: one is the logarithmic periodic oscillation. On a linear scale, 
the closer to the critical time, the faster the oscillation frequency. The second is power law growth (bubbles) or decay (antibubbles) or superexponential growth or decay, that is, the growth rate of prices is not constant but monotonically increases (bubbles) or decreases (antibubbles). So, it can be considered that the LPPL model gives a quantitative method for judging the bubble and antibubble.

3.2. LPPL Model. Due to the mutual imitation of traders and the formation of the herd effect through positive feedback, the price has a nonlinear vibration, which is similar to a logarithmic periodic vibration so that the final collapse of the bubble risk is explained by market dynamics.

Log periodicity is a significant signal law for discrete scale invariance (DSI) of complex systems. Theoretically, the law of scale invariance often appears near the critical point of a system. Although this phenomenon is not a necessary characteristic for the critical point of the system, the behavior of the critical point of the system can still be observed through the analysis of the law of invariance of the scale. For a variable $O(x)$, its discrete scale invariance characteristic is reflected when the independent variable $x$ becomes the original double. The form of $O(x)$ remains the same, which is $O(x)=\mu(\lambda) O(\lambda x)$. The invariance actually comes from the power law form of $O(x)$. This is consistent with the laws of fractals and multifractals. In order to reflect the periodicity of $\lambda, O(x)$ can be of the form:

$$
O(x)=x^{\alpha}
$$

where $P(\ldots)$ is any function with periodicity. Therefore, this periodic function can be expanded with a Fourier series; the series form is as follows:

$$
\begin{array}{r}
\sum_{n=-\infty}^{\infty} c_{n} \exp \left(2 n \pi i \frac{\ln x}{\ln \lambda}\right), \\
a_{n}=a+i \frac{2 \pi n}{\ln \lambda} .
\end{array}
$$

Substituting the series expansion into the $O(x)$ formula, the first-order form is

$$
I(t)=A+B \tau^{\alpha}+C \tau^{\alpha} \cos [\omega \ln \tau+\phi],
$$

where $I(t)$ is the price time series of the financial market, which can be the original price series or the logarithmic price series, $I(t)=P(t)$ or $I(t)=\ln P(t)$; the final fitting results obtained by the two are almost the same, but generally the logarithmic price series is used. $\tau$ is the time interval from the critical point, $\tau=t_{c}-t$ is a bubble curve, $\tau=t-t_{c}$ is a reverse bubble curve, and $t_{c}$ is the tipping point. In order to diverge the risk of a bubble burst at a tipping point and to limit prices, $0<\alpha<1$. Sometimes in order to fit more finely, a second-order term is added:

$$
\begin{aligned}
I(t)= & A+B \tau^{\alpha}+C \tau^{\alpha} \cos [\omega \ln \tau+\phi] \\
& +D \tau^{\alpha} \cos \left[2 \omega \ln \tau+\phi_{2}\right]
\end{aligned}
$$

where $A=\ln [\omega(t)]>0$ means that if the bubble continues to a critical time $t_{c}$, the value of $\ln P\left(t_{c}\right)$ will be reached; $B$ refers to the increase in $\ln P\left(t_{c}\right)$ per unit time when $C$ is close to 0 before the crash; $C$ is a measure of the fluctuation amplitude around the exponential growth; $t_{c}>0$ is the time when the bubble bursts and the critical time $t>t_{c}$ is any time before the bubble bursts; $m$ is the exponential of power growth; $\omega$ is the angular frequency of the bubble phase oscillation; and $0<\phi<2 \pi$ is the initial phase of the shock.

The logarithmic periodic power law model is a relatively successful model developed by economic physicists from the observation of the economic bubble phenomenon $[18,19]$ and has been adopted by many financial institutions. It is inherently difficult to analyze and make predictions about the bubble trend in financial markets. Economists often make predictions just when the bubble is about to burst. Sornette made an analogy from the earthquake research and analyzed the formation of bubbles in the financial market in depth. He proposed the LPPL model and was able to predict the critical time point. However, as a complex system, financial markets have scale invariability near the critical point, but in the actual development process, how to use models to avoid risks and minimize the losses caused by the burst of the bubble still requires many people to seriously consider things.

\subsection{Fitting Process. Essentially,}

$$
y_{i}=A+B\left(t_{c}-t_{i}\right)^{\beta}+C\left(t_{c}-t_{i}\right)^{\beta} \cos \left[\omega \ln \left(t_{c}-t_{i}\right)+\phi\right] .
$$

This is a highly nonlinear equation with 7 parameters to be evaluated. We generally use curve fitting to get the parameters of the model. Faced with as many as 7 parameters to be estimated in the model, we need to fit these parameters, and highly nonlinear functions need to be carefully considered, and what is considered is to ensure that the best fitting results are obtained (underprepared fit or overfit is not good).

We know that the so-called parameter fitting [20] is nothing more than an objective function minimization problem. Here, our objective function is the sum of the squares of the errors between the calculated value $Y_{i}$ of the LPPL model and the actual observed value (price):

$$
\begin{aligned}
\mathrm{SE} & =\sum_{t=t_{1}}^{t_{n}}\left(y_{t}-\widehat{y}_{t}\right)^{2} \\
& =\sum_{t=t_{1}}^{t_{n}}\left\{y_{t}-A-B\left(t_{c}-t\right)^{\beta}\left(1+C \cos \left(\omega \log \left(t_{c}-t\right)+\varnothing\right)\right)\right\}^{2} .
\end{aligned}
$$

When there are too many parameters to be estimated, the objective function will have multiple local minima. In addition, because of the noisiness of the fitting sample, we directly fit the 7 parameters, and we will fall into the misunderstanding of local solution. In previous studies, many 
scholars suggested using 1stopt $[21,22]$ in China to perform 7-parameter fitting. However, research shows that even a general global algorithm such as 1stopt, which does not need to set an initial value, cannot guarantee that the result obtained is the global minimum. After many experiments, one of the alternative ideas is to use the variant 1stop solution:

$$
\left(y_{i}-A\right)\left(t_{c}-y_{i}\right)^{-\beta}=B+C \cos \left[\omega \ln \left(t_{c}-t_{i}\right)+\varnothing\right] .
$$

In fact, we used the default LM + UGO algorithm to perform 10 fittings, and the parameters obtained obviously converge to 3 different intervals because if there is no range constraint, there will be multiple sets of solutions in theory.

Therefore, trying to reduce the number of parameters to be estimated becomes the first task of LPPL fitting. To reduce the number of fitted free parameters, the three linear parameters $(A, B$, and $C)$ in the LPPL are compressed to the remaining four nonlinear parameters $\left(t_{c}, \beta, \phi\right.$, and $\left.\sigma\right)$. According to the objective function, after the partial derivatives of three linear parameters $(A, B$, and $C)$ are obtained, the derived derivative formula should be 0 when the minimum value is obtained, and we can get simultaneous equations.

Specifically, first rewrite the LPPL equation as follows:

$$
\begin{aligned}
& y_{i}=A+B f_{i}+C g_{i}, \\
& f_{i}=\left(t_{c}-t_{i}\right)^{\beta}, \\
& g_{i}=\left(t_{c}-t_{i}\right)^{\beta} \cos \left[\omega \ln \left(t_{c}-t_{i}\right)+\phi\right] .
\end{aligned}
$$

Then, the equations can be obtained as follows:

$$
\left(\begin{array}{l}
\sum_{i=1}^{N} y_{i} \\
\sum_{i=1}^{N} y_{i} f_{i} \\
\sum_{i=1}^{N} y_{i} g_{i}
\end{array}\right)=\left(\begin{array}{ccc}
N & \sum_{i=1}^{N} f_{i} & \sum_{i=1}^{N} g_{i} \\
\sum_{i=1}^{N} f_{i} & \sum_{i=1}^{N} f_{i}^{2} & \sum_{i=1}^{N} f_{i} g_{i} \\
\sum_{i=1}^{N} g_{i} & \sum_{i=1}^{N} f_{i} g_{i} & \sum_{i=1}^{N} g_{i}^{2}
\end{array}\right)\left(\begin{array}{l}
a \\
b \\
c
\end{array}\right) .
$$

The above equations can be solved by standard LU decomposition [23] to obtain $A, B$, and $C$. In this way, we can use 4 nonlinear parameters to represent 3 linear parameters. After the operation of the aforementioned slave parameters, we reduced the number of parameters to be estimated from 7 to 4 .

After that, we generally use the taboo + LM algorithm to perform the fitting to get the final result.

\section{Case Study of A-Share Disaster}

China's A-share market has ushered in a long-lost bull market after a 7-year bear market. Due to the typical leverage characteristics of this round of bull market, in less than a year, the transaction volume of the two markets has exceeded 1 trillion to 20,000. The index also raised a double within one year. Fanatic funds have blown up a huge bubble in the A-share market. The stock market bubble is often caused by the herd effect of investors [24, 25]. Therefore, we can observe China's A-share market by describing indicators related to investor behavior in the stock market to see the bubble situation of the stock market.

4.1. Bubble Burst. The Chinese economy has shifted from being largely closed to being a major player in the world, mainly through large-scale investment in real estate and infrastructure over the past three decades. From 2000 to 2008 , China's average annual GDP growth rate was $13 \%$, but it has slowed to $7.8 \%$ in 2009 and around $7 \%$ after 2015 . With this rapid growth, from May 2005 to October 2007 and from November 2008 to August 2009, the Chinese stock market experienced dynamic changes in the roller coaster. The latest bubble started around mid-2014 and recently began to collapse in mid-June 2015, commonly known as the stock market disaster.

The last bubble reached almost $150 \%$ growth in just one year. As China's real estate market cools down sharply as a whole, China's stock market has grown even more dramatically. This bubble can be seen as the result of powerful leverage that is disconnected from the reality of economic activity and corporate returns. About $7 \%$ of China's population has been active in the stock market frenzy, from easy access to credit to investing in the stock market.

An interesting feature of the Chinese stock market is that insurance companies and pension funds have traditionally stabilized investors through buying and holding strategies, which basically do not exist in the field of Chinese investment. As a result, about 90 million small- and medium-sized investors have become the main driving force of the stock market and are more vulnerable to rumors, imitations, speculation, and crowds. In fact, there are many signs that the Chinese government has encouraged small retail investors to invest in the stock market, driving it for some time, but also catalyzing its vulnerability.

4.2. Early Warning and Analysis of Bubble Burst. Since the high point on June 12, 2015, the SSEC has fallen by $32 \%$ since reaching the bottom on July 8, 2015, and has fluctuated significantly since then. The smaller Shenzhen stock market has fallen $41 \%$ over the same period. The Chinese government has taken unprecedented measures to stop the decline. In particular, the People's Bank of China has repeatedly lowered the benchmark loan and deposit interest which was at an all-time low point. In addition, more measures have been taken like relaxing funding rules, announcing a moratorium on suspension of new IPO, investigating malicious short selling and so on. Before the stock index began to fall sharply in mid-June, there were obvious signs in the A-share market, especially the daily volatility, turnover rate, and unprecedented trading volume.

Taking the last trading day in May as an example, the amplitude throughout the day is as high as 300 points, which is more than $7 \%$. Then, entering the middle of June, the market began a plunge pattern. SSE Composite Index fell from a maximum of 5178 to 3507 , a drop of $31 \%$. The GEM index and the SME index were also spared. The SME index fell $33 \%$, and the GEM index plummeted $40 \%$. During the stock market disaster, the total market value of A shares lost 
a total of 25 trillion yuan, so that the surge in A shares from early 2015 to mid-June was brought to naught.

When the fuse was lit after the SEC cracked down on OTC allocations, the market entered a plunge mode. First, a large number of funding accounts were forcibly closed. Because of the leverage of $1: 5$ or even $1: 10$, a slight breeze in the market is also unacceptable for such accounts. When a large number of funded accounts reach the warning line, in order for the funded company to protect its own funds, the computer will automatically sell a large number of stocks, leading to the emergence of a limit tide. Under the slump, the Chinese government has adopted several rounds of rescue measures, including interest rate cuts and transaction costs, but these measures failed because they did not touch the essence of the crisis.

The failed bailout triggered a frontal collapse of confidence and a second round of plunge, which led to the collapse of the two financial accounts of major securities firms and a large number of liquidation lines. A large number of liquidation positions were sold on the daily limit board, which eventually formed a vicious circle. On the other hand, the net values of major private equity companies like Qingshuiyuan, continued to fall during the crash. Some of them reaching the liquidation line 0.7 , were forced to liquidate. Larger public offering funds are facing a severe tide of redemption, and the sharp sell-off of assets in an inherently illiquid market is undoubtedly fueling the fire.

As the stock market continued to plummet in mid-June, the Chinese government began to implement a number of market rescue policies in order to stabilize the market and prevent the occurrence of local financial crises [26-28]:

(1) On June 26, the Shanghai Composite Index recorded a $74 \%$ drop. The next day, the People's Bank of China announced that starting from June 28 , financial institutions would cut interest rates by $0.25 \%$, while targeting downwards by 0.256 .

(2) Two days later, due to the market's downward trend, the two major exchanges announced at the same time that they would reduce the transaction costs of the stock market.

(3) After the plunge, the CSRC announced that it would relax the restrictions on margin financing and securities lending. The discount rate and the liquidation line can be determined by the securities firms.

(4) On July 3, the CSRC issued an announcement that it was necessary to reduce the number of new shares issued under the current situation.

(5) On July 3, the China Securities Regulatory Commission issued an announcement saying that Central Huijin Investment Co., Ltd. has invested funds to rescue the market.

(6) After one day, a number of securities companies jointly expressed their confidence in the market and actively used their own funds to support the market.
(7) On July 4, more than 20 large securities firms announced joint funding to purchase not less than 120 billion yuan of financial real estate index constituents in the secondary market.

(8) On the evening of July 4, under the influence of the State Council, 28 companies that had planned to be listed on the Shanghai and Shenzhen stock exchanges were suspended from IPO, and all investors were returned with frozen subscription funds.

(9) On July 5, 2015, the People's Bank of China announced that it will provide adequate liquidity support on the balance sheet of China Securities Finance Corporation, and on the same day, the China Securities Regulatory Commission confirmed that China Securities Finance Corporation would buy ETF.

(10) On July 5, 2015, the China Financial Futures Exchange imposed restrictions on opening futures markets, especially short positions, and imposed penalties on naked short positions.

From the stock disaster to the rescue of the market, in 2015, A shares staged a war that is hard to see in Hollywood. Among those strategies, the sweeping of stocks by 'the State Team' is the most noticeable. The "Equilibrium Fund" swept A shares in the process of saving the market and gave birth to rebounding demonic stocks such as Meibang Clothing and Luoyang Glass. According to Wande data, as of the end of September, among the top ten circulating shareholders of China's A-share companies, China Securities Finance Co., Ltd. and Central Huijin Investment Co., Ltd. appeared in more than 1,300 of them, accounting for about 49\% (560 from the Shanghai Stock Exchange, 232 from the Shenzhen Stock Exchange, 353 from the SME Board, and 217 from the GEM). The amount of funds used to purchase A shares accounted for about $8 \%$ of the total A shares outstanding.

\subsection{Descriptive Statistical Characteristics of A-Share Market} Returns. From the statistics of returns of Table 1, it can be seen that the yield index of the Shanghai Composite Index has the characteristics of spikes and fat tails, that is, the probability of extreme returns is large.

4.4. Significance of Liquidity. Market liquidity can be defined from two aspects: one is the liquidity of assets and the other is the liquidity of liabilities. In short, the liquidity of assets is the time cost and money cost of turning it into money. Time cost refers to the time it takes to realize. If investors who urgently need currency need to obtain it after one-month liquidity, then this asset is obviously not a liquid asset. At the same time, the high cost of money for realizing money also means low liquidity, and the liquidity of liabilities is the difficulty and cost of financing. In case of the A-share market, as long as the stock is not at the limit, the time and cost of liquidation can be ignored. However, due to the design of the $T+1$ trading system, the liquidity of the A-share market is naturally lower than the mature $T+0$ 
TABLE 1: Descriptive statistics of A-share returns.

\begin{tabular}{lc}
\hline Mean & 0.097819 \\
\hline Median & 0.37415 \\
\hline Maximum value & 5.7635 \\
\hline Minimum value & -8.4909 \\
\hline Standard deviation & 2.636989 \\
\hline Skewness & -0.792691 \\
\hline Kurtosis & 4.196858 \\
\hline
\end{tabular}

market because the stocks bought on that day can only be sold the next day, which means that the overall time cost of A shares is higher than that in other markets.

4.5. Analysis. The occurrence of this round of stock disasters was a series of liquidity crises caused by leveraged funds entering the stock market, financing, and other account bursts [29-31].

Looking back at the policies implemented by the government at the time of the stock market crash, most of them did not touch on the substance of the problem, but instead, the collapse of confidence caused by the ineffectiveness of the policy led to a second decline. For example, the entry of pensions into the market is a long-term process. It is impossible to require pensions to pick up the market for the country, resulting in deeper lock-in and causing greater problems. Therefore, the entry of pensions into the market has no effect on the settlement of short-term liquidity. Reducing transaction settlement costs is even more irrelevant. The suspension of the IPO has eased the thawing of some financing funds, but it has not had a great effect on the problems on the market. More than 20 brokerage companies invested 120 billion yuan to buy blue-chip ETFs and to lift PetroChina by the end of the year, and other measures could not solve the SME board and the ChiNext board in the hardhit areas of liquidity, as well as various small- and mediumsized market value stocks. In addition, increasing the QFII quota has not shown good results because foreign capital comes in time, and it does not come to play a role in unwinding the financing disk. Even for a small interest rate cut and RRR cut, the effect is not significant because the release of the interest rate cut effect takes time, and the market's expectations of most interest rate cuts have been reflected in the stock price. At this time, interest rate cuts cannot drive the stock market out of liquidity crisis.

The bull market marked by the behavior of risk-free interest rates has experienced a surge in interest rates, and the logic of being long has collapsed. At the same time, leveraged funds have grown and cannot be ignored. Sensitive speculators will lose their way with a bit of wind. For highly leveraged accounts, one or two daily stops will lead to an automatic liquidation. So far, a model of a liquidity spiral has been formed as shown in Figure 6.

In contrast, after the market closed on July 8th, the securities company injected 200 billion yuan into five public funds, immediately welcoming the positive response of the Hong Kong stock market at night. Moreover, the stock

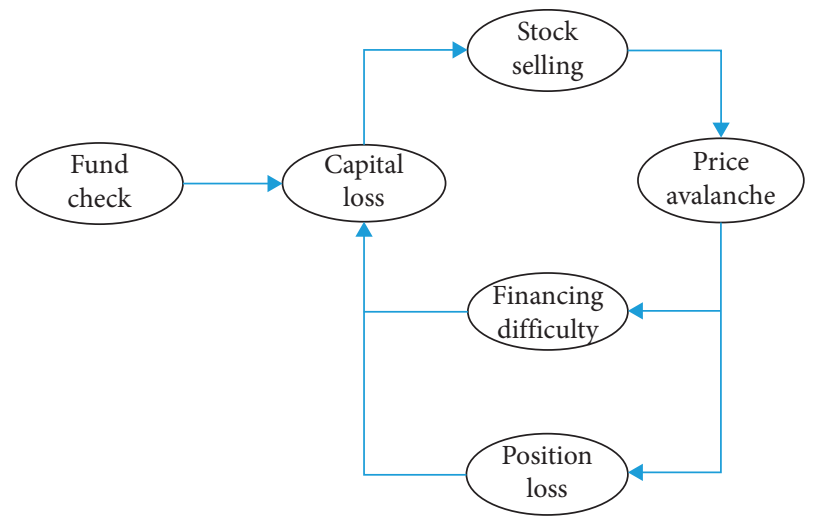

FIgURE 6: Liquidity spiral.

market rose sharply for two consecutive days since then, and the panic was relieved. This is a result of the policy responds positively to the liquility issues. These 200 billion yuan can help ease the huge redemption tide facing the fund and cut off the spread of the liquidity crisis. Moreover, compared with government officials, public fund practitioners know the market better and know what stocks to buy, which is more reasonable than Huijin's direct purchase of large corporate stocks.

In view of this, in the future, if a liquidity crisis occurs again, this article proposes the following short-term emergency measures:

(1) The People's Bank of China publicly promises to provide sufficient liquidity to major commercial and securities companies.

(2) The People's Bank of China shall lead the establishment of the leveling fund, which must be large in scale and fast in timing.

(3) Prohibit malicious suspension of trading to prevent secondary depletion of liquidity. The above has analyzed the bad consequences caused by the malicious suspension of trading during the 2015 A-share stock disaster.

The entire stock disaster went from brewing to occurrence to deterioration to mitigation. It can be said that various policy errors have occurred. To avoid the recurrence of future tragedies, various systems need to be established and perfected. Therefore, this article proposes the following three policy recommendations for discussion:

(1) It can also be seen in the analysis of the entire stock market disaster that in the beginning of June before the stock market disaster, the market was already in an extremely bubbling state. At this time, the interest rate of the money market rose sharply due to factors such as seasonal bank deposits. The central bank has tightened liquidity through targeted measures, but the CSRC chose to strictly check the funding at this time instead of choosing a time when these funds were not tight in March and April. It can be said that because the supervision system of the three parties 
and the three associations also has greater responsibility for this stock disaster, it is urgent to establish a comprehensive financial supervision institution.

(2) Improve the existing arbitrage system [32, 33] to avoid loopholes in the trading system.

(3) Leveraged funds played an important role in this round of the stock disaster. We must learn from domestic and foreign experiences to improve the supervision of leveraged funds. The United States has many years of history of funding, but they have strict restrictions on the subject of funding. Many penny stocks and too high-risk stocks cannot be bought in leveraged accounts [34]. At the same time, the source of leveraged funds is not only securities firms, but also banks, trusts, private loans, etc., so comprehensive financial regulators are required to supervise cross-border funds.

\section{Conclusive Remarks}

In this paper, we propose a method of dynamic feedback early warning based on big data, which uses the LPPL model to fit parameters. We evaluate the performance of real-time diagnostics, economic theory bubbles based on rational expectations, imitation of behavioral mechanisms, and the mathematical expressions. Finally, we used this method to analyze the case of the A-share disaster. The research results show that the method makes the early warning coefficients of dynamic and complex systems more scientific and accurate to meet the needs of China's financial sector at this stage.

In the future, more big data technologies will be considered for dynamic complex system early warning. For example, a unified open source platform for distributed online machine learning will be built to collect and analyze data in the economic field; more prediction models will be integrated into the platform as an analysis lib tool; more realtime suggestions will be given to use big data analysis and comprehensive decision-making methods. These works will bring new dividends to the early warning of complex systems.

\section{Data Availability}

The data used to support the findings of this study are available from the corresponding author upon request.

\section{Conflicts of Interest}

The authors declare that they have no conflicts of interest.

\section{Acknowledgments}

This research was supported by the Program of the CoConstruction with the Beijing Municipal Commission of Education of China (grant no. B18H100040).

\section{References}

[1] M. Mitchell, "Complex systems: network thinking," Artificial Intelligence, vol. 170, no. 18, pp. 1194-1212, 2006.

[2] W.-X. Zhou and D. Sornette, "Antibubble and prediction of China's stock market and real-estate," Physica A: Statistical Mechanics and Its Applications, vol. 337, no. 1-2, pp. 243-268, 2004.

[3] M. Crouhy, G. Dan, and R. Mark, "A comparative analysis of current credit risk models," Journal of Banking \& Finance, vol. 24, no. 1-2, pp. 59-117, 2000.

[4] D. Sornette, Why Stock Markets Crash: Critical Events in Complex Financial Systems, Vol. 49, Princeton University Press, Princeton, NJ, USA, 2017.

[5] S. Davis, "The adverse feedback loop and the effects of risk in both the real and financial sectors," vol. 66, Federal Reserve Bank of Dallas, Washington, DC, USA, 2010.

[6] I. Logojan, "Explanations of financial crises in the classic theory and in the theory of reflexivity," Review of the Air Force Academy, vol. 2, p. 71, 2009.

[7] I. Vrecko, J. Kovac, B. Rupnik, and B. Gajsek, "Using queuing simulation model in production process innovations," Int. Journal of Simulation Modelling, vol. 18, no. 1, pp. 47-58, 2019.

[8] D. T. Pele, "An LPPL algorithm for estimating the critical time of a stock market bubble," Journal of Social and Economic Statistics, vol. 1, no. 2, pp. 14-22, 2012.

[9] A. Johansen and D. Sornette, "Financial "anti-bubbles": logperiodicity in gold and Nikkei collapses," International Journal of Modern Physics C, vol. 10, no. 4, pp. 563-575, 1999.

[10] L. M. Wang, Z. Y. Hao, X. M. Han, and R. H. Zhou, "Gravity theory-based affinity propagation clustering algorithm and its applications," Tehnicki Vjesnik-Technical Gazette, vol. 25, no. 4, pp. 1125-1135, 2018.

[11] Z. Ma and S. Xiao, "Closed form valuation of vulnerable European options with stochastic credit spreads," Economic Computation And Economic Cybernetics Studies And Research, vol. 53, no. 4, pp. 293-311, 2019.

[12] F. J. Carmone and P. E. Green, "Model misspecification in multiattribute parameter estimation," Journal of Marketing Research, vol. 18, no. 1, p. 87, 1981.

[13] D. Blazquez and J. Domenech, "Big data sources and methods for social and economic analyses," Technological Forecasting and Social Change, vol. 130, pp. 99-113, 2018.

[14] V. G. Chumak, V. M. Ramzaev, and I. N. Khaimovich, "Challenges of data access in economic research based on big data technology," CEUR Workshop Proceedings, vol. 1490, 2015.

[15] N. M. S. Algheriani, V. D. Majstorovic, S. Kirin, and V. Spasojevic Brkic, "Risk model for integrated management system," Tehnicki Vjesnik-Technical Gazette, vol. 26, no. 6, pp. 1833-1840, 2019.

[16] G. Shabat, Y. Shmueli, A. Averbuch, and Y. Aizenbud, "Randomized lu decomposition," Applied \& Computational Harmonic Analysis, vol. 44, no. 2, 2013.

[17] E. Comăniţă, P. Cozma, I. Simion, M. Roşca, and M. Gavrilescu, "Evaluation of eco-efficiency by multicriteria decision analysis. case study of eco-innovated and ecodesigned products from recyclable waste," Environmental Engineering and Management Journal, vol. 17, pp. 1791-1804, 2018.

[18] K.-S. Moon and H. Kim, "Performance of deep learning in prediction of stock market volatility," Economic Computation 
and Economic Cybernetics Studies And Research, vol. 53, no. 2, pp. 77-92, 2019.

[19] M. Spatareanu, V. Manole, and A. Kabiri, "Do bank liquidity shocks hamper firms' innovation?” International Journal of Industrial Organization, vol. 67, Article ID 102520, 2019.

[20] S. Figlewski, "Hedging performance and basis risk in stock index futures," The Journal of Finance, vol. 39, no. 3, pp. 657-669, 1984.

[21] D. Zhang, "High-speed train control system big data analysis based on fuzzy RDF model and uncertain reasoning," International Journal of Computers, Communications \& Control, vol. 12, no. 4, 2017.

[22] D. Zhang, J. Sui, and Y. Gong, "Large scale software test data generation based on collective constraint and weighted combination method," Tehniki Vjesnik, vol. 24, no. 4, pp. 1041-1049, 2017.

[23] S. Jiang, M. Lian, C. Lu, Q. Gu, S. Ruan, and X. Xie, "Ensemble prediction algorithm of anomaly monitoring based on big data analysis platform of open-pit mine slope," Complexity, vol. 2018, Article ID 1048756, 13 pages, 2018.

[24] S. Hido, S. Tokui, and S. Oda, "Jubatus: an open source platform for distributed online machine learning," in Proceedings of the NIPS 2013 Workshop on Big Learning, Lake Tahoe, NV, USA, December 2013.

[25] B. N. Silva, M. Diyan, and K. Han, "Big data analytics," in Deep Learning: Convergence to Big Data Analytics, pp. 13-30, Springer, Singapore, 2019.

[26] B. Jan, H. Farman, M. Khan et al., "Deep learning in big data analytics: a comparative study," Computers \& Electrical Engineering, vol. 75, pp. 275-287, 2019.

[27] R. Iqbal, F. Doctor, B. More, S. Mahmud, and U. Yousuf, "Big data analytics: computational intelligence techniques and application areas," Technological Forecasting and Social Change, vol. 153, Article ID 119253, 2020.

[28] M. Haslett, "Dynamic feedback system and method for providing dynamic feedback," U.S. Patent Application 15/ 6936142019-3-7, 2019.

[29] C. Diks, C. Hommes, and J. Wang, "Critical slowing down as an early warning signal for financial crises?" Empirical Economics, vol. 57, no. 4, pp. 1201-1228, 2019.

[30] J. Janekova, J. Fabianova, and M. Fabian, "Assessment of economic efficiency and risk of the project using simulation," International Journal of Simulation Modelling, vol. 18, no. 2, pp. 242-253, 2019.

[31] P. Wang, L. Zong, and Y. Ma, "An integrated early warning system for stock market turbulence," Expert Systems with Applications, vol. 153, Article ID 113463, 2020.

[32] A. G. Barkish, T. Salari, and N. Salehnia, "Analysis and modeling of the substantial fall of Tehran stock exchange in January 2014 using the log-periodic power law (LPPL) model," Journal of Economic Research, vol. 153, pp. 97-124, 2019.

[33] O. I. Krivosheev, "Log-periodic power law autonomous stock market model," in Proceedings of the 2019 Twelfth International Conference "Management of Large-Scale System Development" (MLSD), IEEE, Russia, Moscow, pp. 1-5, October 2019.

[34] S. Harsha and B. Ismail, "Review on financial bubbles," Statistical Journal of the IAOS, vol. 35, no. 3, pp. 501-510, 2019. 